\title{
Always Alert for the Unpredictable: Experiencing and Treating Migraine ${ }^{1}$
}

\author{
Rebeca Veras de Andrade Vieira ${ }^{2}$ \\ Universidade Federal do Rio Grande do Sul, \\ Porto Alegre-RS, Brazil \\ Luciana Karine de Souza \\ Universidade Federal do Rio Grande do Sul, \\ Porto Alegre-RS, Brazil
}

\author{
Gustavo Gauer \\ Universidade Federal do Rio Grande do Sul, \\ Porto Alegre-RS, Brazil \\ William Barbosa Gomes \\ Universidade Federal do Rio Grande do Sul, \\ Porto Alegre-RS, Brazil
}

\begin{abstract}
Migraine is a disease with serious impacts on quality of life. We conducted a phenomenological qualitative inquiry in order to understand how 10 female patients with migraine dealt with their disease and its treatment, at a headache unit of a reference hospital. Through a phenomenological analysis, we highlighted seven themes that connected participants' experiences to those reported in the previous literature. We noticed that participants recurrently described their migraine experiences through metaphors. The communicative metaphors indicated an overarching theme of constant vigilance for the unpredictable. Participants felt lack of empathy from others during headache episodes, and showed ambivalence about several aspects of treatment. Our interpretation is that addressing to how patients communicate about their illness might help health professionals to establish stronger therapeutic alliances based on empathy and respect. Professionals' communication skills are the primordial resource to facilitate adherence to treatment and its success.
\end{abstract}

Keywords: migraine headache, phenomenology, health psychology

\section{Sempre Alerta para o Imprevisível: Experiência e Tratamento da Enxaqueca}

\begin{abstract}
Resumo: A enxaqueca é uma doença com sérios impactos à qualidade de vida. Conduzimos uma pesquisa qualitativa fenomenológica para compreender como 10 pacientes mulheres com enxaqueca lidaram com sua doença e o tratamento em um ambulatório de cefaleia de um hospital de referência. Através de análise fenomenológica, obtivemos sete temas que conectaram as experiências das participantes àquelas reportadas na literatura. Percebemos que as pacientes recorrentemente descreveram experiências usando metáforas. As metáforas comunicativas apontam para o tema principal vigilância constante para o imprevisivel. As participantes sentiram falta de empatia dos outros durante episódios de enxaqueca e mostraram ambivalência sobre vários aspectos do tratamento. Nossa interpretação é que abordar a forma de os pacientes comunicarem sua doença pode auxiliar profissionais de saúde a estabelecerem alianças terapêuticas fortes baseadas em empatia e respeito. As habilidades comunicativas dos profissionais são o recurso primordial para facilitar a adesão ao tratamento e seu sucesso.
\end{abstract}

Palavras-chave: enxaqueca, fenomenologia, psicologia da saúde

\section{Siempre Atento a lo Impredecible: Experiencia e Tratamiento de la Jaqueca}

\begin{abstract}
Resumen: La jaqueca es una enfermedad con impactos importantes en la calidad de vida. Realizamos un estudio cualitativo fenomenológico para entender cómo 10 pacientes mujeres con jaqueca lidian con la enfermedad y tratamiento, en un servicio ambulatorio de jaqueca en un hospital de referencia. A través del análisis fenomenológico obtuvimos siete temas que relacionan las experiencias de las participantes con aquellas relatadas en la literatura. Notamos que las participantes describieron sus experiencias de jaqueca de forma recurrente a través de metáforas. Las metáforas señalaron el tema principal vigilancia constante para lo impredecible. Las participantes manifestaron sentir falta de la empatía de los demás durante los episodios de jaqueca y ambivalencia sobre diversos aspectos del tratamiento. Nuestra interpretación es que tratar de la manera como el paciente se comunica acerca de la enfermedad puede ayudar a los profesionales de salud a establecer alianzas terapéuticas fuertes basadas en empatía y respeto. Las habilidades comunicativas del profesional son el recurso primordial para facilitar la adhesión al tratamiento y su éxito.
\end{abstract}

Palabras clave: jaqueca, fenomenología, psicología de la salud

Migraine is a primary headache, clinically characterized by intermittent headache attacks of moderate to intense pain, lasting from four to 72 hours, with often unilateral location

\footnotetext{
${ }^{1}$ Paper deriving from the master's thesis of the first author, under the advice of the second author, and co-advised by the fourth author, defended in the PostGraduate Program of Psychology at Universidade Federal do Rio Grande do Sul. Support: National Council of Scientific and Technological Development (CNPq, Grant \# 483702/2013-7).

${ }^{2}$ Correspondence address: Universidade Federal do Rio Grande do Sul. Programa de Pós-Graduação em Psicologia. Rua Ramiro Barcelos, 2600, Rio Branco, Porto Alegre-RS, Brazil, CEP 90.035-003. E-mail: rebecavieirapsico@gmail.com
}

(Headache Classification Committee of the International Headache Society, 2013). It considerably impairs patients' quality of life, often causing temporary work incapacitation and affecting daily activities. The impact of migraine is pervasive and encompasses different life domains, from dissatisfaction with physical health, work, and interpersonal relationships to deficits in cognitive processing (Leonardi, Raggi, Bussone, \& D'Amico, 2010; Vladetić, Jančuljak, Butković Soldo, Kralik, \& Buljan, 2017).

In addition to medication, the choice treatment of 
patients with chronic pain, such as in migraine, includes the modification of beliefs, attitudes, values, and behaviors. The ability to identify internal states, understand them, and be able to communicate them is critical for developing effective strategies for pain management and adherence to treatment. Peters, Abu-Saad, Vydelingum, Dowson, and Murphy (2005) have highlighted changes that need to be implemented in health care. Greater involvement of patients in their own care may be the key for many undertreated migraine patients. Expanding knowledge from the patients' perspective is useful for health professionals in order to adapt their clinical practice with headache patients.

For Buse and Andrasik (2009), migraine remains underestimated, underdiagnosed and undertreated. The authors argued that it is mandatory to improve communication between health professionals and patients. They also suggested active listening to the patients' speech and use of open-ended questions to allow the elaboration of a more appropriate and realistic therapeutic plan, specific for each case. These strategies were associated with fewer consultations.

Although quantitative studies with large populations are very informative and specify the main factors associated with the disease, psychometric instruments that seek to measure such processes, while useful, sometimes fail to provide specific strategies that encompass more individual, detailed differences. In this sense, qualitative approaches offer an in-depth understanding of migraine. Interviews conducted by Peters, Abu-Saad, Vydelingum, Dowson, and Murphy (2004) showed that patients with migraine and chronic daily headache adapted headache management to suit their needs and preferences, making pain management highly individual. Del Monaco (2013), using a grounded theory approach, conducted interviews with 38 adult migraine patients. The author reported that, among other statements, attitudes such as put up with pain and carry on were a response to a moral pressure felt by the patients against the idea of using headache as an excuse or lie. Along with this reasoning, some patients mentioned that there are better motives for consulting with a physician than a headache. Meyer (2002) found out in female patients a vigilant behavior identified as the art of watching out. Patients would employ vigilance as part of the decision making process to remain functioning in the face of unpredictable migraine attacks.

Dekker et al. (2012) used thematic analysis data generation, and results suggested that the main factors that interfere on migraine patients' decision to undergo preventive treatment. They were self-determination; balancing pros and cons; perceived burden of migraine; and earlier interventions carried out by the patient. Varkey, Linde, and Henoch (2013), using a qualitative content analysis, also concluded that for migraine prevention benefit patients, they need to fully accept that this prevention will influence their lives to some degree. This requires "assuming control over the effects of pain and role functioning" (p. 843). These results emphasize the importance of involving patients in their own care, taking their story as valuable sources of information to plan their treatment and return to patients the sense of control over their disease.

Ramsey (2012) conducted a qualitative study in order to better understand how eight women lived with migraine headache. Individual interviews were analyzed under a combination of a hermeneutic-phenomenological inquiry and story theory. The analysis generated seven interrelated themes that described the lived experiences in terms of "reshaped life, vulnerable self, torturous pain, pushing through to hold self together, seeking relief of the torturous pain, getting on with life, and being on guard" (Ramsey, 2012, p. 307).

A hermeneutic-phenomenological approach also guided the study conducted by Rutberg, Öhrling, and Kostenius (2013), in which 19 adults with migraine responded to an interview on how to manage life satisfactorily while living with migraine. The authors depicted two main themes: building a foundation of safeness, and amplifying the good in life. In addition to preventive strategies, the study provided evidence on the role of promoting positive attitudes in the daily life of migraine patients.

Qualitative inquiry via first-person perspective may help to generate data, in depth and range, useful for research specialists, health professionals, patients, and people on their relationship networks. Phenomenological methods are an option still underused in research about migraine. The sample of migraine patients in Rutberg et al. (2013) included data from patients undergoing physical therapy, yet without a specific approach into the treatment variable (e.g., types of treatments, satisfaction, medication). Ramsey's (2012) inquiry reported that some participants were under health care for migraine, but no further details were provided on this matter.

The present study reports a qualitative inquiry that describes and discusses how migraine patients experience their disease and its treatment at a headache unit in a Brazilian reference hospital. Using a phenomenological approach, we aimed at understanding patients' assessments on treatment, adherence, and medication use. Our main interest was to explore themes and meanings in the context of treatment and in the experience of living with migraine.

\section{Method}

This is a qualitative inquiry in a phenomenological tradition. The study of conscious experience involves a process of reduction. Reduction derives from the researcher's suspension of previous judgments on the issues under study. Consequently, this allows for regarding participants' lived experience without assuming the content of their expression as truth, but grasping the intentionality of such experience. Such intentionality comprises the varieties in modes of presentation by which experience presents itself to consciousness (Gomes, 2007). As Gergen (2014, p. 51) puts it: "phenomenologists are concerned with understanding others' experiences in their own terms - thus drawing themselves closer to their subjects, ... in hopes of establishing genuine understanding".

\section{Participants}

We recruited 10 women diagnosed with migraine without aura, among the outpatients enrolled at the headache unit of a reference public hospital in southern Brazil. This unit has a frequency of 20 patients per week. The sample was 
obtained by convenience, through invitation, according to the calendar order of appointment. The patients' age range was 30 to 59 years and the time living with migraine ranged from 2 to 47 years. They had been under treatment for migraine for a period between 1 to 20 years.

\section{Instruments}

The interview designed for this study constitutes in a protocol of topics with a flexible sequence of questions, distributed in four parts: treatment/impact of the disease, experience of having migraine, history of the relationship with the pain, and current relationship with the pain. A short set of demographic questions preceded the interview.

\section{Procedure}

Data collection. The first author conducted individual interviews at the hospital, in an appropriate office designated for research. Interviews occurred in a single session, on the same day of the doctor's appointment at the headache unit. They lasted for about an hour, were audio-recorded, and later transcribed for analysis. Participation was voluntary, with all ethical guarantees granted (confidentiality, privacy, anonymity, freedom to terminate participation at any time without any penalty, etc.). All participants gave informed written consent prior to their inclusion in the study.

Data analysis. Analysis by the phenomenological method comprises three steps: description, reduction, and interpretation (Gomes, 2007). In description, the researcher attempts to describe the research object without any previous conceptions, by suspending personal and theoretical judgments. In the present study, this first step generated 10 descriptions, one per participant. A consensus between first and second authors completed the description phase. The reduction step operates upon the content of description. The goal is to extract what is invariant in the phenomenon, by discarding elements without compromising an understanding of the communicational structure of the object of study. Technically, in reduction, the demarcation of units of meaning respects the native terms used by the participants. Nonetheless, the researcher further transforms them into analytical terms, and unites them in categories of meanings.

In this study, reduction produced seven main themes that accounted for the structure of the phenomenon. Agreement between the authors concluded the reduction step. The third, final step of the phenomenological method is interpretation. It constitutes the analytical understanding of the structure of the phenomenon, departing from the description and reduction created from participants' reports, toward how the data relate to the available empirical and theoretical literature on the psychological processes involved in the participants' relationship with their disease and its treatment.

\section{Ethical Considerations}

This study was approved by the Research Ethics Committee of the Hospital de Clínicas de Porto Alegre (HCPA, protocol number 110116).

\section{Results}

The seven main themes revealed by reduction were: (a) pain, a sensation that alters the entire self; (b) understanding the disease; (c) what goes through my mind during a migraine episode; (d) the burden of migraine in my life; (e) treating migraine; (f) coping with headache, every resource; and (g) empathy, counting on others. For each theme we provide evidence that we believe better represents the reduction undertaken.

\section{Pain: A Sensation that Alters the Entire Self}

Migraine is a terrible pain that leads to a severe difficulty to act or think about anything during a crisis. Furthermore, unpredictable headaches affect planning of anything with short-, medium-, or long-term duration. As Participant 2 (P2, for short) puts it, "Sometimes I feel like doing something, and on the very same day I think about doing something, on that day comes the headache. Then, I end up doing what? Nothing! I don't do anything".

Patients received feedback from persons with whom they interacted on a daily basis. For those persons, mood changes, physical symptoms, and the way patients started to interact with them showed that the pain is present: "Of course people see, because we feel apathetic, with no strength to do things, right? Even talking, I try to avoid talking, because it bothers me, it hurts. It is very noticeable" (P8).

When in pain, migraine patients perceived different negative reactions from people. In response to this, participants felt anger and wanted to avoid social contact, mostly because they felt misunderstood. Instead of admitting that their behavioral change was due to a crisis, they chose to say that it was due to something else, not the pain.

Participants considered pain as a highly subjective phenomenon and hard to understand by other people: "Because I get quite depressed sometimes, someone asks me 'Are you sad?'. . People from the countryside are like this, somewhat indiscrete. 'No, it is nothing like that; I am just a little tired"' (P4).

\section{Understanding the Disease}

The women interviewed expressed a strong will to deepen their understanding of migraine, its etiology, prognosis, triggers, and associated factors: "If you look at it in technical terms, that is one thing, but my understanding is that migraine is a very strong pain. However, why it has no cure, why it happens ... hat I would also like to know" (P1).

In trying to understand and manage pain, the participants reported having conducted quite a few experiments on their own. Sometimes they even hurt themselves:

And I used to hit, hit my head on the wall, I would stand still and keep hitting ... Hit, hit, it hurt and didn't solve anything. If I told you that I slept like a bat, I would lie in bed with my head hung upside down off the bed to see if, you know, something would get better (P6). 
Earlier attempts to understand the disease led to fear that pain was as a symptom of other diseases. This brought upon a fear of death:

I already told the doctor that I am afraid, ok. I had a colleague a few years ago, I did not even know she had migraine ... Then they said that she was watching TV, a pain came on, she fell down, they took her to the hospital, she died. Then I associated that with migraine, because I did not know she had it, but the doctor says no one dies of migraine (P6).

Throughout the interviews, there were descriptions of pain via metaphors: "If one wire touches another, does it touch a wire, like electricity, when it touches, there is shock? Is that it? . . Because if now I have no pain, soon it comes . . . is it a wire touching another?" (P2). "It seems like, the feeling I get is that someone grabs a knife and starts sticking it in you. It is an unbearable pain" (P10).

Participants pointed out the need for information besides the diagnosis. They wanted to expand their understanding of the disease and develop new skills for effective pain management:

I did not know what it was, I did not know, I thought it was a headache, but did not know what it was. For me, it was a headache ... I do not know. It is the pain, the overwhelming pain, and then the doctor said it was migraine, but I want to find out why, how it appears, why it appeared, what is the cause (P3).

\section{What Goes Through my Mind during a Migraine}

The thoughts evoked during migraine attacks were conversations of the participants with themselves - internal conversations - about which coping strategy to adopt during the crisis: "I am thinking 'Oh my, which is better? This never goes away, it will never go away. How long will I be like this?' You have to take medication, you want to die . . Looking for ways to stop the pain" (P6).

During crises, migraine sufferers reported feeling sad. This was associated to an impossibility of keeping appointments, or meetings, and acting according to plans:

Oh, it gives much sorrow; you get very sad, right . . Hum, there are things you cannot do, right . . What joy can someone with pain feel? None, (laughter) none. I do not know anyone with a joyful pain" (P3). Migraine attacks made participants feel lost, small, and beaten up: "Loss, loss . . . You feel very small, tiny, you know ... Aggression. That is what goes through [my mind], I can tell you (P9).

\section{The Burden of Migraine in my Life}

Migraine affected distinct life dimensions. It was responsible for work absences and decrease in productivity. In addition, pain led to mood alterations, affecting patients' ability to feel pleasure and plan their daily lives:

Any part of your body can hurt, but when your head hurts, you lose the ability to work, to do anything, you cannot reason in any way. You want . . . you beg to die. You don't eat, you don't go for a stroll, you don't talk to anyone, you don't do business, you don't work, you don't smile, you don't live (P4).

The worst problems for migraine patients were: (a) inability to accomplish anything when in pain; (b) feeling misunderstood and disrespected; (c) experiencing associated symptoms; (d) suffering social isolation; and (e) inability to plan and fulfill certain commitments:

I think it [migraine] does not leave you free to do whatever you want. Often you feel like doing something, and at the time when you start doing that, the headache comes and stops you from doing that, because it does not let you do anything, when you have a very strong pain, you cannot do it (P2).

The need to be in a constant state of alert was a characteristic of the experience of living with migraine:

I think she is a person [migraine patient], who has no peace, she is a person always alert to something, because now this person is well and soon she will not be. Then, this person never leaves home peacefully. The person has to carry her medicine, she has to leave always prepared, because she can be okay now and in a little while, she is not, right? So she has to always be alert (P2).

No one is to blame for the pain. Participant 1 spoke about feeling very angry during migraine attacks. As an alternative to assaulting someone, she directed her aggression against herself, through biting or nipping. This woman considered selfaggression a better strategy compared to assaulting others:

I had that pain, that pain, and he [another patient] spoke and, by God, I was going to hit him . . . I bit myself, I bit myself, the pain was so strong, I bit myself all over. You know, if I could not hit someone I felt like biting myself, I bit myself. Not nowadays. I am more civilized, I go there, sit down, pinching myself, but it is horrible (P1).

\section{Treating Migraine}

The understanding of the treatment goals ranged from toleration to cure. There is ambivalence about treatment: sometimes satisfactory, sometimes frustrating. Frustration 
came when prescribed medications did not work as participants expected. It was also very frustrating for them:

I have been like this for the last 20 years. My expectations of getting better would improve if some treatments that I have done, or have been doing ... had shown good outcomes, or the crisis would lessen, I mean, less intense. Then, well, it would be working out, right? . . . As things are, I am going to die like this. Oh, the same thing of seeing no solution. I will die like this, I will die in pain (P6).

Participants were also ambiguous about medication. They considered it effective for migraine relief. Nonetheless, the side effects frustrated them:

It's bad, because you take medication for one thing, and it's bad for something else, right? It's complicated, very complicated. If you take medication for headache, you spoil your stomach ... It's hard to find medication that works for one thing and does not harm another (P8).

Sometimes, intense pain brought despair and an impulse to take several medications. The aim was to get relief, despite knowing that medication abuse was inadequate: "Then I take everything I have in the kitchen, all the medications I have. I know it's wrong, that it will not work, but the pain is so strong that I despair" (P1). The same woman shared her resistance to taking medication:

Nobody likes to take medicine. I am a person not even a bit hypochondriac. There are times when I decide not to take them anymore, and I don't. I do that for two, three days and then I go crazy. Then I take it (P1).

The participants went to several medical clinics before enrolling in the headache unit. Other medical specialties, hence, recommended the unit:

The gastroenterologist referred me here, for my bowl symptoms, she recommended it. I always wondered why I had headaches, so that is why she sent me to the headache treatment. Up to when they sent me [here], I already had strong crises at home. I think it took me a year until they called me. It took, took too long (P1).

For some participants, migraine treatment would not have started if there were no other health issues in need of treatment: "If I knew [there was treatment for migraine], I would not have suffered as much as I did (laughter). I would have come a long time before" (P3).

The need to seek treatment for migraine came from the intensity of the pain, the discomfort from associated symptoms, the severe psychological distress, the need for a differential diagnosis, the ineffectiveness of painkiller intake (without medical supervision), and instruction to address other health issues. However, after years of disease, treatment adherence got associated with hope for pain relief, the appreciation of participants themselves, the possibility of taking care of family members, no more need to be isolated, and the desire to live better. Thus, it is clear that throughout the course of the disease, the motivation to adhere to treatment expanded from pain relief to improvement of quality of life: "Pain annoys me, but I have to go on, take care of my mother, my father ... And my grandson as well, his future, these things concern me a lot ... Family is everything to me" (P4).

In the beginning of treatment, all participants expected to be cured:

It is what I want, right? I don't know. One day, suddenly, I'll come here [at the hospital] and they will say to me 'You are cured, you will never have headaches again'. Everyone comes here with this same purpose, it is what people imagine, that they'll never have it [headache] again (P1).

Participants understood that health professionals are trained to cure. Because migraine often involves a chronic disease, participants realized they could not blame health professionals for treatment failure. However, expectations regarding cure could still affect the patient-health professional relationship: "It is horrible, because I think it has been more than 20 years that this has been happening, and there is no way to be cured, there is no way to make this pain go away. I even think the doctors might be incompetent" (P6).

\section{Coping with Headache: Every Resource}

Besides medical treatment, participants also performed various actions to manage their migraines: trying to stay calm, not worrying too much, remaining in the dark, applying ice to the head, regulating what they ate, resting, avoiding to go out, praying, having acupuncture, pressing their hands against the head, stretching and doing physical activity, trying to remain still, and getting massages. There were preventive actions concerning prescribed medications. In addition, migraine sufferers mentioned avoiding places where there is too much light or where temperature is too high. They considered preventive actions less effective, since pain was unpredictable.

Sense of self-efficacy for pain management differed among participants. Some women believed to have strategies to deal with pain: "I try to take a deep breath, I retreat, I lie down a little, I try not to go out, I drink a lot of fluid" (P4). Other patients reported that they could do nothing about it: "It's horrible, the pain is horrible. So what do I do? There is nothing to do, you understand?" (P9).

\section{Empathy: Counting on Others}

In the participants' view, pain is a highly subjective phenomenon and difficult for other people to understand. 
They felt misunderstood, and censured for expressing how discomforting the pain was: "Usually people think that I am faking it. . . you know? That it is pretense, that I don't have anything" (P9).

They also mentioned that only people with migraine understood this experience. Participant 6 felt that treatment only worked in other patients, but not in her; Hence the belief that she was the only person in the world to have a terrible headache, with no possible pain relief:

I see it on television . . people, you know, how they live with headache ... In one case, the doctor treated it and the case was solved, you know, the pain became very sporadic. In another person, the pain diminished a lot, another one followed that treatment. And I, it's been 20 years and no one solves my case, no one gives me the right medication ... But it seems I am the only person in the world, this is something that I believe in, I am the only person in the world who has this terrible pain (P6).

\section{Discussion}

Our goal was to identify patients' assessments on treatment, adherence, and the medication they received in a headache unit of a reference hospital. We interviewed 10 women with migraine and explored their meanings regarding experiences of living with migraine. The semioticphenomenological approach shed light upon participants' own perspective and ways of dealing with the treatment and coping with the disease. Results showed how they felt misunderstood by others.

Throughout the interviews, we observed that many participants' descriptions of pain presented themselves in the form of metaphors and metonymies. In metaphor, a term is used in place of another and their relationship is of similarity (e.g., a sedentary person is a "couch potato"). In metonymy, the original term is substituted by one of its parts ("his wheels" to refer to one's car). The pervasive role of metaphors in the perceptual, cognitive, affective and expressive aspects of construing experience has been extensively explored since the work of George Lakoff and Mark Johnson in early 1980 's. Here we choose to focus on the analysis of specific applications of metaphor to chronic pain management.

Through the metaphoric and metonymic linguistic tropes, a person may employ alternative signifiers in a connotative stance in order to impart meanings. This is useful when subjective experiences with varying qualities and intensity such as headaches are to be expressed. Pain, as distressful and subjective as it may be, ought to be admitted to other people in order to be acknowledged and understood in a relational context. In health care contexts, the ways patients express pain interfere on the patient-doctor communication. A communicational failure is often responsible for treatment failure, as well as for the patients' feelings of loneliness and of being misunderstood. Some authors, because of the use of metaphors and metonymies, have advocated successful communication of the invisible experience of migraine, when migraine patients describe pain to other persons (Gallagher, McAuley, \& Moseley, 2013, Semino, 2010).

Metaphors (and metonymy) seem to be an important tool toward empathy (Semino, 2010) and reconceptualization of the illness (Gallagher et al., 2013). In the context of migraine, communication via linguistic tropes may help others to come closer to understand a different kind of pain, in the headache realm (Semino, 2010). This may be crucial for a successful patient-physician relationship.

Gallagher et al. (2013) used metaphor training as a tool to reduce patients' catastrophizing and to promote reconceptualization of their chronic pain condition. In a randomized controlled trial, they obtained significant results in a metaphor training intervention. The authors state that treatments should include working with metaphors since the beginning, because they engage emotional responses and demand that clients attend to meanings of the disease and their reorganization. In the present study, we found frequent, spontaneous metaphor use in the open context of an interview by migraine patients attempting to make their experience understood. This can be taken to indirectly covalidate Gallagher et al.'s claims. Besides reconceptualizing meanings in chronic pain, metaphors seem to play a role in communicating them. In other words, metaphors help people in making their experiences more comprehensible to themselves as well as to others.

During migraine crises, participants expressed the thoughts they usually had in the form of internal conversation, which helped to choose better strategies to manage pain. Studies show that internal conversations help to solve complex problems (Da Silveira, De Souza, \& Gomes, 2010). Regarding pain management as a complex task, internal conversation may be a valuable tool for migraine sufferers.

Among the worst consequences of living with migraine were the unpredictability of attacks and the resulting sense of losing control over the situation. This finding is in line with data from Dekker et al. (2012) and Ramsey (2012). Furthermore, as indicated in the literature, unpredictability has been a central axis of the experience of living with migraine. As Rutberg and Öhrling (2012) mentioned, repeatedly canceling appointments due to migraine episodes is more difficult than the symptoms themselves. People with migraine lose the will to do things and interact with other people.

Regarding coping strategies toward migraine, our participants mentioned a constant state of alert. Those findings are in line with Meyer's (2002) discussion on the art of watching out, as well as Ramsey's (2012) finding of being on guard. Constant vigilance improves decision making in the context of unpredictable attacks. The alert state, in fact, relates to the unpredictability aforementioned.

Some participants felt frustrated with the medications prescribed for not working as expected. Moreover, our participants reported fear of side effects from medication; and, hence were unwilling to take them. Peters et al. (2004) identified those same behaviors and beliefs towards medication. Thus, our findings agree with previous studies highlighting the importance of clear, constant dialogue 
between patients and healthcare professionals. Physicians who are previously aware of such attitudes may be able to access migraine patients' distorted expectations for prognosis and offer valuable information about the disease (Buse \& Andrasik, 2009).

Health professionals' core representation of migraine as a disease also interferes on the medical history of the patients. As Montali, Monica, Riva, and Cipriani (2011) pointed out, when treating chronic pain sufferers, health professionals tend to focus on the organic nature of the pain and leave the patients' subjective experience in the background.

Moreover, there are indications that, misled by the idea that pain is a symptom and not a disease itself, our subjects postponed seeking treatment at an earlier stage. Koffman, Morgan, Edmonds, Speck, and Higginson (2008) identified different meanings attributed to pain in cancer patients: a challenge, a test of faith, an enemy, a punishment. Those findings suggest that new studies are needed to shed light on this interval between the onset of the disease and the initiation of treatment.

The patients' motivation is an important factor for success of treatment for migraine (Buse \& Andrasik, 2009). In the present study, some motivations were being cured and no longer needing medication. These contents, when not discussed with the health team, might lead to frustration and even treatment drop out.

The women we interviewed expected to be cured at the beginning of treatment. Thus along with motivation, health professionals should investigate the expectations concerning treatment in order to design a realistic plan with the patient. Given the close relationship between expectation and satisfaction, work on such expectations may also alleviate the frustration that is so common in these patients.

Participants noticed a lack of empathy from people they interacted with when in pain. They felt misunderstood and censured when expressing discomfort. These findings are consistent with Rutberg and Öhrling's (2012), in which female migraine patients fear that others may not believe they are indeed in pain. Communicating useful information about migraine to family members, relatives, friends, and coworkers - the patients' relationship network - might be useful.

On the other hand, the ability to express what one feels could be responsible for feeling misunderstood. This lack of empathy might be due to other reasons. First, there is the challenge of communicating a complex phenomenon like pain. Studies have shown characteristics of alexithymia in migraine patients (Vieira, Vieira, Gomes, \& Gauer, 2013). This could be responsible for influencing the ability to distinguish feelings from body sensations, and to express feelings through words. Second, Cohen, Quintner, Buchnan, Nielsen, and Guy (2011) have already pointed out that lack of empathy may allow the manifestation of negative community stereotypes concerning chronic pain sufferers, and add to their stigmatization. With no discernible evidence of injury, an individual might believe to be simply dealing with a disturbed mind.

We would like to point to two limitations in our research. First, we investigated female patients only. We did not address male perspectives on living with migraine. Future migraine studies should consider this, since men and women differ significantly in terms of health issues (Baker et al., 2014). Second, participants were under treatment on a specialized headache unit at a reference hospital. Thus, their experiences might be distinct from those of treated elsewhere or without medical supervision (or diagnosis).

In hope of contributing to the advance of the psychological understanding of people living with migraine, we believe our study was unique in terms of how participants expressed their ideas, during migraine attacks, as internal conversation. That was a facilitator in choosing an adequate strategy to deal with pain. Migraine patients may cope more effectively with pain by engaging in internal conversation.

Health psychologists might benefit from longer and deeper interview protocols that access the patients' thoughts and feelings about not only the disease, pain, and related difficulties, but also concerning communication about the migraine with people on their relationship network. Health teams need to know about misguided attitudes toward treatment, and other associated themes, in order to replace them with correct and realistic information.

Our results reflect and detail the complexity of an experience that interferes on the way patients relate to themselves and others, with considerable impact on their daily lives. The patients' role is not only to adhere to treatment; they may also develop theories about their own situation, identifying environmental, psychological, and somatic factors associated with the disease. Furthermore, because patients have firsthand knowledge, they may negotiate coping strategies, treatment management, and self-monitoring. Migraine sufferers know their disease better than anyone else; how it alters themselves, their relationships, and whether they see themselves as migraine patients.

The phenomenological approach allowed us to describe the structural aspects of the experience of being a woman with migraine. The results showed the importance of taking into account the first-person perspective for the clinical work with migraine, especially regarding attitudes of individuals toward prevention, treatment management and adherence.

Our results emphasize the importance of health professionals assess issues that go beyond the raw description of symptoms and pain characteristics. Listening to the patients' thoughts and beliefs, as well as employing strategies for pain management, is a valuable tool to understand each case. Moreover, when approaching the patient's perspective, health professionals can establish a therapeutic alliance based on empathy and respect, which, in turn, facilitates adherence and treatment success.

\section{References}

Baker, P., Dworkin, S., Tong, S., Banks, I., Shand, T., \& Yamey, G. (2014). The men's health gap: Men must be included in the global health equity agenda. Bulletin of the World Health Organization, 92(8), 618-620. doi:10.2471/ BLT.13.132795 
Buse, D. C., \& Andrasik, F. (2009). Behavioral medicine for migraine. Neurologic Clinics, 27(2), 445-465. doi:10.1016/j.ncl.2009.01.003

Cohen, M., Quintner, J., Buchnan, D., Nielsen, M., \& Guy, L. (2011). Stigmatization of patients with chronic pain: The extinction of empathy. Pain Medicine, 12(11), 1637-1643. doi:10.1111/j.1526-4637.2011.01264.x

DaSilveira, A. C., DeSouza, M. L., \& Gomes, W. B. (2010). "Falar com seus botões": Pelos meandros teóricos e empíricos das relações entre conversa interna, reflexividade e self ["Talking with my buttons": The ins and outs on the theoretical and empirical relations among internal conversation, reflexivity and the self]. Estudos de Psicologia (Natal), 15(3), 223-231. doi:10.1590/S1413294X2010000300001

Dekker, F., Neven, A. K., Andriesse, B., Kernick, D., Reis, R., Ferrari, M. D., \& Assendelft, W. J. J. (2012). Prophylactic treatment of migraine; the patient's view, a qualitative study. BMC Family Practice, 13, 13. doi:10.1186/14712296-13-13

Del Monaco, R. (2013). Autocuidado, adherencia e incertidumbre: Tratamientos biomédicos y experiencias de pacientes en el dolor crónico de la migraña [Self-care, adherence and uncertainty: Biomedical treatments and patients' experiences regarding chronic migraine pain]. Salud Colectiva, 9(1), 65-78. Retrieved from http://www. scielo.org.ar/pdf/sc/v9n1/v9n1a06.pdf

Gallagher, L., McAuley, J., \& Moseley, G. L. (2013). A randomized-controlled trial of using a book of metaphors to reconceptualize pain and decrease catastrophizing in people with chronic pain. Clinical Journal of Pain, 29(1), 20-25.doi:10.1097/AJP.0b013e3182465cf7

Gergen, K. J. (2014). Pursuing excellence in qualitative inquiry. Qualitative Psychology, 1(1), 49-60. doi:10.1037/ qup0000002

Gomes, W. B. (2007). Distinção entre procedimentos técnico e lógico na análise fenomenológica [Distinction between technical and logical procedures on phenomenological analysis]. Revista da Abordagem Gestáltica, 13(2), 228240. Retrieved from http://pepsic.bvsalud.org/pdf/rag/ v13n2/v13n2a07.pdf

Headache Classification Committee of the International Headache Society. (2013). The International Classification of Headache Disorders, 3rd edition (beta version) [ICHD-3 beta]. Cephalalgia, 33(9), 629-808. doi: $10.1177 / 0333102413485658$

Koffman, J., Morgan, M., Edmonds, P., Speck, P., \& Higginson, I. (2008). Cultural meanings of pain: A qualitative study of Black Caribbean and White British patients with advanced cancer. Palliative Medicine, 22(4), 350-359. doi:10.1177/0269216308090168
Leonardi, M., Raggi, A., Bussone, G., \& D’Amico, D. (2010). Health-related quality of life, disability and severity of disease in patients with migraine attending to a specialty headache center. Headache, 50(10), 1576-1586. doi:10.1111/j.1526-4610.2010.01770.x

Meyer, G. A. (2002). The art of watching out: Vigilance in women who have migraine headaches. Qualitative Health Research, 12(9), 1220-1234. doi:10.1177/1049732302238246

Montali, L., Monica, C., Riva, P., \& Cipriani, R. (2011). Conflicting representations of pain: A qualitative analysis of health care professionals' discourse. Pain Medicine, 12(11), 1585-1593. doi:10.1111/j.15264637.2011.01252.x

Peters, M., Abu-Saad, H., Vydelingum, V., Dowson, A., \& Murphy, M. (2004). Migraine and chronic daily headache management: A qualitative study of patients' perceptions. Scandinavian Journal of Caring Sciences, 18(3), 294-303. doi:10.1111/j.1471-6712.2004.00279.x

Peters, M., Abu-Saad, H., Vydelingum, V., Dowson, A., \& Murphy, M. (2005). The patients' perception of migraine and chronic daily headache: A qualitative study. Journal of Headache and Pain, 6(1), 40-47. doi:10.1007/s10194005-0144-7

Ramsey, A. R. (2012). Living with migraine headache: A phenomenological study of women's experiences. Holistic Nursing Practice, 26(6), 297-307. doi:10.1097/ HNP.0b013e31826f5029

Rutberg, S., \& Öhrling, K. (2012). Migraine: More than a headache: Women's experiences of living with migraine. Disability and Rehabilitation, 34(4), 329-336. doi:10.310 9/09638288.2011.607211

Rutberg, S., Öhrling, K., \& Kostenius, C. (2013). Travelling along a road with obstacles: Experiences of managing life to feel well while living with migraine. International Journal of Qualitative Studies on Health and Well-being, 8, 1-9. doi:10.3402/qhw.v8i0.19900

Semino, E. (2010). Descriptions of pain, metaphor, and embodied simulation. Metaphor and Symbol, 25(4), 205226. doi:10.1080/10926488.2010.510926

Varkey, E., Linde, M., \& Henoch, I. (2013). "It's a balance between letting it influence life completely and not letting it influence life at all": A qualitative study of migraine prevention from patients' perspective. Disability \& Rehabilitation, 35(10), 835-844. doi:10.3109/09638288. 2012.709304

Vieira, R. V. A., Vieira, D. C., Gomes, W. B., \& Gauer, G. (2013). Alexithymia and its impact on quality of life in a group of Brazilian women with migraine without aura. The Journal of Headache and Pain, 14, 18. doi:10.1186/11292377-14-18 
Vladetić, M., Jančuljak, D., Butković Soldo, S., Kralik, K., \& Buljan, K. (2017). Health-related quality of life and ways of coping with stress in patients with migraine. Neurological Sciences, 38(2) 295-301. doi:10.1007/ s10072-016-2759-7

Rebeca Veras de Andrade Vieira holds a Ph.D. from the Universidade Federal do Rio Grande do Sul, Brazil.

Gustavo Gauer is a Professor of the Instituto de Psicologia of the Universidade Federal do Rio Grande do Sul, Brazil.

Luciana Karine de Souza is a Post-Doctoral Researcher of the Universidade Federal do Rio Grande do Sul, Brazil.

William Barbosa Gomes is a Senior Fellow of the Universidade Federal do Rio Grande do Sul, Brazil.

Received: Mar. 23, 2017

1st Revision: Sep. 15, 2017

Approved: Oct. 18, 2017

How to cite this article:

Vieira, R. V. A., Gauer, G., Souza, L. K., \& Gomes, W. B. (2017). Always Alert for the Unpredictable: Experiencing and Treating Migraine. Paidéia (Ribeirão Preto), 27 (Suppl. 1), 413-421. doi:10.1590/1982-432727s1201706 